\title{
Social class differences in years of potential life lost: size, trends, and principal causes
}

\author{
David Blane, George Davey Smith, Mel Bartley
}

\begin{abstract}
British social class differences in mortality are examined in terms of years of potential life lost, a measure that gives more weight to deaths that take place at younger ages. It shows wider class differences during the years of working life than those found when mortality is expressed in terms of standardised mortality ratios. Examination of the change in class differences between 1971 and 1981 for all causes of death combined and for the three categories of death which during these ages make a major contribution to total years of potential life lost shows complex changes. Inequalities in years of potential life lost have increased between 1971 and 1981, during which all the principal causes of death have shown stationary or rising rates among the manual classes. The use of years of potential life lost as a measure of population health trends focuses attention on the major contribution of violent death, which occurs mainly in younger men, to widening class differences in mortality.
\end{abstract}

\section{Introduction}

We used years of potential life lost to examine the size, trends, and importance of different causes of death in social class differentials in mortality. Years of potential life lost is a measure of mortality that takes account of the age at death as well as the fact of death itself. It was developed in the 1940 s and ' 50 s, when the conventional mortality rate in its various forms was being criticised on the grounds that it was "influenced by the relative stability of the mortality rates at the older ages and does not permit sufficient weight to be given to the differences in mortality at younger ages, which are so important when viewed from the aspect of the amount of life lost." Haenszel calculated the effect on the years of potential life lost of using different age ranges $(1-65,1-75$, etc), and all were found to accentuate differences in mortality with time and between areas in a more pronounced manner than the standardised death rate. Thus years of potential life lost is a particularly sensitive measure of mortality differences where these differences occur in younger age groups. Haenszel ${ }^{1}$ and Doughty ${ }^{2}$ also advocated the use of this measure on the grounds that it was easily understandable. For example, the years of life lost to age 65 from all cancers was 8.9 per 1000 in 1940 in the United States, ${ }^{1}$ which easily translates into an average of 0.0089 years $(3 \cdot 2)$ days per person.

In the 1940s and '50s Dempsey ${ }^{3}$ and Greville ${ }^{4}$ used years of potential life lost to assess the contribution of deaths caused by tuberculosis to total mortality, and Doughty $^{2}$ and Logan and Benjamin ${ }^{5}$ used it to examine the way in which mortality had changed over time. Of particular relevance to our study, Dickinson and Welker modified the measure to investigate working years lost in the age band 20-65 years. ${ }^{6}$ More recently, years of potential life lost has been used to examine the relative importance of different causes of death in Italy, ${ }^{7}$ France, ${ }^{8}$ and the United States. ${ }^{9}$ In addition, the measure is used routinely in examining data on cause of death by the Office of Population Censuses and Surveys in Britain and by the Centers for Disease Control in the United States. As far as we can discover, however, this measure has not been used previously to examine social class differences in mortality. This is surprising, given that class differences in mortality tend to be greater in the younger than in the older age groups; years of potential life lost may therefore be a particularly appropriate measure.

\section{Methods}

The data from which the rates of years of potential life lost were calculated were obtained from the microfiches attached to the 1971 and 1981 occupational mortality supplements. ${ }^{1011}$ Age adjusted rates were calculated according to the method described by Romeder and $\mathrm{McWhinnie},{ }^{12}$ in which the age adjusted rate of years of potential life lost per 1000 population equals

$$
\sum_{i}^{{ }^{65}} a_{i}\left(\frac{d_{i}}{P_{i}}\right)\left(\frac{P_{i r}}{N_{r}}\right) \times 1000
$$

where $a_{i}=$ remaining years to live until age 65 when death occurs between ages $i$ and $i+1$ (that is, 65-(i+ $0 \cdot 5)$ ), assuming uniform distribution of deaths within age groups; $d_{i}=$ number of deaths between ages $i$ and $i+1 ; P_{i}=$ number of persons of age $i$ in the actual population; $P_{i r}=$ number of persons of age $i$ in the reference population; and $\mathrm{N}_{\mathrm{r}}=$ number of persons between ages $i$ and 65 in the reference population. In other words, the age adjusted rate of years of potential life lost sums the age specific mortality weighted according to years of life lost and directly standardised to a reference population to allow comparison of populations possessing different age structures. The 1981 census population of England and Wales was chosen as the standard population in the present study.

The rates of years of potential life lost vary with the age ranges examined, which allows for precise comparison of these rates only when they are derived from the same age range. Table I illustrates this technical property of the measure by comparing social class differences in the rates of years of potential life lost for four age ranges. The comparison shows that the rates of years of potential life lost become greater when the upper limit of the age range is increased and smaller when the lower limit is decreased. This characteristic seems to be counterintuitive. It results from low mortality in children and adolescents; including them expands the denominator more than the numerator, despite each death contributing many years of potential life lost.

Dr Blane.

Br Med f 1990;301:429-32 
As the work reported in this paper compared different time periods and genders it was important to obtain data sets for men and women of the same age range for 1971 and 1981. Unfortunately this was not possible from the published data on occupational mortality. Data for 1971 were available for both men and women for the age range 15-64 years, but in 1981 the range was from 16 for both sexes to 59 for women and 64 for men. The data needed to correct these deficiencies were obtainable in only one instancenamely, deaths from all causes for 15 year old men in 1981. For 1981 the years of potential life lost for men aged 15-64 differed by less than $1 \%$ from those for men aged 16-64. Obtaining these additional data, therefore, allowed for precise comparison of deaths in men from all causes in 1971 and 1981, and also provided some idea of the margin of error that needs to be borne in mind when interpreting the other results.

\section{Results}

Table II gives direct comparisons of social class differences in the age adjusted rate of years of potential life lost and the standardised mortality ratio for 1981 . As the published standardised mortality ratios are based on the age range 20-64 years for men and 20-59 years for women, the years of potential life lost in this table have also been calculated for ages 20-64 and 2059 . Both measures increase as they move from social class $\mathrm{I}$ to class $\mathrm{V}$, with the ratio of these extremes being

TABLE I-Effect of varying age range on years of potential life lost. Annual age adjusted rate per 1000 population by social class (men only) for all causes of death in Great Britain 1979-80 and 1982-3

1-74 Years ${ }^{\star}$ 1-64 Years ${ }^{\star}$ 20-74 Years 20-64 years

\begin{tabular}{lrrrr}
\hline Social class: & & & & \\
I & 70 & 31 & 91 & 39 \\
II & 82 & 37 & 104 & 45 \\
III Non-manual & 93 & 45 & 125 & 57 \\
III Manual & 114 & 51 & 147 & 63 \\
IV & 123 & 59 & 156 & 72 \\
V & 176 & 91 & 225 & 114
\end{tabular}

^Assuming that deaths between ages 1 and 15 years are equally divided between boys and girls.

TABLE II-Comparison of social class differences in years of potential life lost (per 1000 population) and standardised mortality ratio; 1981 data for Great Britain

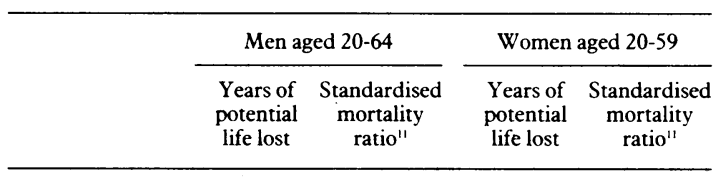

\begin{tabular}{lcccc}
\hline Social class: & & & & \\
I & 39 & 66 & 16 & 69 \\
II & 45 & 76 & 18 & 78 \\
III Non-manual & 57 & 94 & 22 & 87 \\
III Manual & 63 & 106 & 23 & 100 \\
IV & 72 & 116 & 27 & 110 \\
V & 114 & 165 & 34 & 134 \\
Ratio of classes V:I & $2 \cdot 9$ & $2 \cdot 5$ & $2 \cdot 1$ & 1.9 \\
\hline
\end{tabular}

TABLE III - Annual age adjusted rate of years of potential life lost per 1000 population for all causes of death in England and Wales in 1971 and 1981. Figures were standardised to total population of England and Wales 1981

\begin{tabular}{lccccc}
\hline & \multicolumn{2}{c}{ Men } & & \multicolumn{2}{c}{ Women } \\
\cline { 5 - 6 } \cline { 5 - 6 } & $\begin{array}{c}1971 \\
\text { (aged 15-64) }\end{array}$ & $\begin{array}{c}1981 \\
\text { (aged 15-64) }\end{array}$ & & $\begin{array}{c}1971 \\
\text { (aged 15-64) }\end{array}$ & $\begin{array}{c}1981 \\
\text { aged 16-59) }\end{array}$ \\
\hline Social class: & & & & & \\
I & 48 & 37 & & 29 & 13 \\
II & 52 & 42 & & 30 & 15 \\
III Non-manual & 63 & 53 & & 35 & 18 \\
III Manual & 66 & 58 & & 39 & 18 \\
IV & 77 & 68 & & 42 & 22 \\
V & 101 & 103 & & 53 & 28 \\
Ratio of classes V:I & $2 \cdot 1$ & $2 \cdot 8$ & & $1 \cdot 8$ & $2 \cdot 2$ \\
\hline
\end{tabular}

TABLE IV-Annual age adjusted rate of years of potential life lost per 1000 population for deaths from principal causes of years of potential life lost in England and Wales, 1971 and 1981. Figures were standardised to total population of England and Wales 1981

\begin{tabular}{|c|c|c|c|c|}
\hline Social class & $\begin{array}{c}\text { All } \\
\text { causes }\end{array}$ & $\begin{array}{c}\text { Ischaemic } \\
\text { heart disease' }\end{array}$ & $\begin{array}{c}\text { Malignant } \\
\text { neoplasms }\end{array}$ & $\begin{array}{c}\text { Accidents } \\
\text { and violence }\end{array}$ \\
\hline \multicolumn{5}{|c|}{1971 (Men aged 15-64) } \\
\hline I & 48 & 14 & 12 & 10 \\
\hline II & 52 & 15 & 12 & 11 \\
\hline III Non-manual & 63 & 19 & 14 & 11 \\
\hline III Manual & 66 & 18 & 16 & 13 \\
\hline IV & 77 & 19 & 17 & 19 \\
\hline $\mathrm{V}$ & 101 & 21 & 19 & 28 \\
\hline \multicolumn{5}{|c|}{1981 (Men aged 16-64) } \\
\hline I & 37 & 12 & 11 & 10 \\
\hline II & 42 & 14 & 12 & 11 \\
\hline III Non-manual & 53 & 18 & 14 & 11 \\
\hline III Manual & 58 & 20 & 16 & 16 \\
\hline IV & 68 & 21 & 17 & 20 \\
\hline $\mathrm{V}$ & 103 & 29 & 24 & 35 \\
\hline \multicolumn{5}{|c|}{1971 (Women aged 15-64) } \\
\hline I & 29 & 2 & 13 & 4 \\
\hline II & 30 & 2 & 13 & 5 \\
\hline III Non-manual & 35 & 3 & 14 & 5 \\
\hline III Manual & 39 & 4 & 15 & 3 \\
\hline IV & 42 & 4 & 15 & 5 \\
\hline $\mathrm{V}$ & 53 & 5 & 17 & 8 \\
\hline \multicolumn{5}{|c|}{1981 (Women aged I6-59) } \\
\hline I & 13 & 1 & 8 & 3 \\
\hline II & 15 & 1 & 8 & 3 \\
\hline III Non-manual & 18 & 1 & 9 & 4 \\
\hline III Manual & 18 & 2 & 9 & 3 \\
\hline IV & 22 & 2 & 10 & 4 \\
\hline $\mathrm{V}$ & 28 & 3 & 12 & 6 \\
\hline
\end{tabular}

ICD codes 410-414, ninth edition

ICD codes 140-209, ninth edition.

'ICD codes 800-999, ninth edition.

somewhat larger for years of potential life lost than for standardised mortality ratios.

Table III compares social class differences in years of potential life lost in 1971 and 1981. For men the age range 15-64 was used in both years, making precise comparison valid. For women, however, interpretation is complicated by the 1971 data referring to the age range 15-64 and the 1981 data referring to $16-59$. For men aged 15-64 the years of potential life lost for social classes I-IV fell by about 10 per 1000 population between 1971 and 1981; those for social class V moved in the opposite direction, increasing between these years by $2 \%$. Inevitably, therefore, the differential between the extremes, as measured by the class V:I ratio, widened between 1971 and 1981. This phenomenon, however, is not simply due to the increasing years of potential life lost in class $\mathrm{V}$-the class IV:I ratio also widened, though to a lesser extent. A similar widening of inequalities between 1971 and 1981 is also apparent from the data for women, although interpretation is complicated by the different age ranges available for these two periods.

Table IV shows the social class differences for men and for women in the three categories of death that were jointly responsible for most of the total years of potential life lost. The data for men are easier to interpret than those for women. The validity of a direct comparison for men between 1971 and 1981 is undermined by the lower limit of the age range being increased from 15 years in 1971 to 16 years in 1981 . Correction for this difference of one year was possible for all cause mortality, and the change in years of potential life lost which resulted was small, being less than $1 \%$. Within these limits, then, directly comparing men in 1971 and 1981 is reasonable. For women the age ranges in these two years are sufficiently different to invalidate direct comparison.

Certain points from this table stand out. Firstly, the causes of death that have been grouped together under the heading of "accidents and violence" are of comparable importance in terms of years of potential life lost because of ischaemic heart disease and malignant neoplasms. Secondly, the class differences for men 
widened for all three categories of death between 1971 and 1981; the predominant pattern is that the years of potential life lost in the non-manual classes (I to III non-manual) have fallen while those in the manual classes (III manual to V) have increased. Thirdly, in 1971 (for which the data for both men and women refer to 15-64 years and the years of potential life lost are therefore directly comparable) the years of life lost owing to malignant neoplasms were broadly similar for men and women, but men experienced far greater loss of potential life both from ischaemic heart disease and from accidents and violence. Finally, the tables show that the three main categories of death account for a higher proportion of years of potential life lost due to causes in 1981 than 1971 . In 1971 these three categories of death accounted for $76 \%$ of the total years of potential life lost by social class I and $67 \%$ of those lost by class V: in 1981 they accounted for $87 \%$ and $86 \%$ respectively.

\section{Discussion}

Certain methodological issues need to be considered before the findings are discussed. The method of calculating years of potential life lost assumes that the deaths within a specific age group are uniformly distributed across that age group, and this assumption becomes safer as the age group being examined becomes smaller. Unfortunately, mortality data divided into five year age groups were not available, and we used the published data that use 10 year age groups to calculate the years of potential life lost. These calculations, then, depend on the assumption that deaths were evenly distributed across the 10 year age groups. The method also assumes that those who died at, say, age 20 would have otherwise lived until the end of the age range, in this case 65 years. This assumption has been addressed by Haenszel ${ }^{1}$ and by Romeder and McWhinnie, ${ }^{12}$ who compared the above method with results based on life tables. Both showed that the years of potential life lost based on this assumption are closely similar to those based on life tables. Finally, the selection of age 65 as the upper age limit could be criticised on the grounds that it implies that life after 65 years has less value than life at younger ages. This is not so. Rather, drawing the line at 65 allows comparison with social class standardised mortality ratios as well as reflecting the fact that at present 65 years is a realistic minimum expectation of life.

In this paper the size of social class differences has been expressed in terms of the ratio of mortality in social class $\mathrm{V}$ to that in class $\mathrm{I}$. When mortality was measured in terms of years of potential life lost the class $\mathrm{V}: \mathrm{I}$ ratio was found to be larger, and hence the class differences wider, than when mortality was measured by standardised mortality ratios. This difference in $\mathrm{V}: \mathrm{I}$ ratios is unlikely to result from the different methods of standardisation that were used in calculating these two measures because, as has been shown, direct and indirect standardisation produce virtually identical social class gradients in mortality. ${ }^{10} \mathrm{~A}$ far more plausible explanation is that the wider class differences result from the way in which years of potential life lost weight deaths at earlier ages. Like the standardised mortality ratio, the rate of years of potential life lost reflects the higher mortality in the working class, but unlike the standardised mortality ratio it also registers the extent to which death occurs at younger ages. The extent of the widening, as judged by comparing the V:I ratios, may seem small, but the shift from a ratio of 2.5 with the standardised mortality ratio to 2.9 with years of potential life lost raises the estimate of social class V's disadvantage by an amount that is equivalent to $40 \%$ of social class I's total mortality.

This finding is relevant to what the Black report called "artefact" explanations of health inequalities. ${ }^{13}$ The relation between social class and health is conventionally measured in terms of the Registrar General's social classes and standardised mortality ratios. It has already been suggested that the use of the Registrar General's classification may underestimate class differences. ${ }^{14-16}$ This paper suggests that the other conventional measure, the standardised mortality ratio, may do likewise.

Exact comparability between the 1971 and 1981 data was achieved only for male all cause mortality. The use of years of potential life lost with these data confirmed the general improvement in mortality between 1971 and 1981, but it also showed that for social class $\mathrm{V}$ mortality as measured by years of potential life lost actually increased. It is unclear why this should have been different in social class $\mathrm{V}$ in comparison with the other social classes, although it is tempting to think in terms of the formation of an underclass when the rationalisation and reorganisation of British industry started in the mid-1970s.

Arguing against this, however, are the results according to cause of death. The increasing mortality in class $\mathrm{V}$ from ischaemic heart disease and from accidents and violence seems to have been shared by other manual classes. Only the data for men is comparable between 1971 and 1981, although even here the age ranges differ by one year; the correction to the all cause data suggests this will introduce an error of less than $1 \%$. An error of this size cannot account for the results presented in table IV, which show that years of potential life lost for the three principal causes of death either remain stationary or increase for all three manual classes. Any improvement was confined to social classes I to III non-manual.

At the same time the proportion of the total years of potential life lost that was accounted for by the three principal causes of death increased. An examination of the International Classification of Diseases bridging $\operatorname{codes}^{17}$ showed that this could not be an artefact of the introduction of the ninth revision of the classification in 1979. The cause of these changes between 1971 and 1981 is not apparent. The growing predominance of the three principal causes of death at ages 15-64 may be a part of a longterm change in the distribution of disease, in particular the decline in mortality from stroke and respiratory disease. Whether the divergence in mortality is confined to class $\mathrm{V}$ or spreads to include all manual classes will become clearer when data from the 1991 census are available. Given that deaths from causes other than the three principal ones account for only a small proportion of deaths, any further increase in the incidence of ischaemic heart disease, malignant neoplasms, and accidents and violence among the working classes will make a divergence of manual from non-manual classes more likely.

Finally, in terms of loss of potential life, accidents and violence are as important as ischaemic heart disease and malignant neoplasms in the 15-64 age group. This has been known for many years, and several pieces of effective preventive medicine have been enacted. ${ }^{18}$ Despite these measures, however, accidents and violence accounted for an increasing percentage of total years of potential life lost in all social classes between 1971 and 1981. For social class I they constituted $22 \%$ in 1971 and $30 \%$ in 1981 ; for social class $\mathrm{V}$ the corresponding figures were $28 \%$ and $34 \%$. This both suggests the need for new policies and emphasises the importance of those services that, by promptly treating the victims of accidents and violence, can prevent many of these deaths.

We acknowledge the help of the Office of Population Censuses and Surveys, who kindly supplied previously unpublished data. 
1 Haenszel W. A standardised rate for mortality defined in units of lost years of life. Am f Public Health 1950;40:17-26.

2 Doughty JH. Mortality in terms of lost years of life. Can $\mathcal{f}$ Public Health 1951;42:134-42.

3 Dempsey $M$. Decline in tuberculosis: the death rate fails to tell the entire story. American Review of Tuberculosis 1947;56:57-64.

4 Greville TNE. Comments on Mary Dempsey's article on "decline in tuberculosis." American Review of Tuberculosis 1948;57:417-9.

5 Logan WPD, Benjamin B. Loss of expected years of life: a perspective view of changes between 1848-72 and 1952. Monthly Bulletin of the Ministry of Health 1951;12:244-52.

6 Dickinson FG, Welker EL. What is the leading cause of death? American Medical Association Bulletin 1948;64:1.

7 Arca M, di Orio F, Forastiere F, Tasco C, Perruci CA. Years of potential life lost (YPLL) before age 65 in Italy. Am $\mathcal{F}$ Public Health 1988;78:1202-5.

8 Blanchon S, Hill C. Premature mortality in France: relative importance of leading causes of death according to the years of potential life lost. Rev Epidemiol Sante Publique 1988;36:120-7.

9 Stout-Weigand N. Fatal occupational injuries in the United States in 19801984. Scand f Work Environ Health 1988;14 (suppl 1):90-2.

10 Office of Population Censuses and Surveys. Occupational mortality: decennial supplement 1970-72. London: HMSO, 1978. (Series DS No 1.)
11 Office of Population Censuses and Surveys. Occupational monality: decennial supplement 1979-80 and 1982-83. London: HMSO, 1986. (Series DS No 2.) 2 Romeder JM, McWhinnie JR. Potential years of life lost between ages 1 and 70: an indicator of premature mortality for health planning. Int $f$ E pidemiol 70: an indicator
$1977 ; 6: 143-51$.

13 Black D. Inequalities in health: report of a working group. London: HMSO, 1980.

14 Marmot MG, Rose G, Shipley M, Hamilton PJS. Employment grade and coronary heart disease in British civil servants. $\mathcal{f}$ Epidemiol Community Health 1978;32:244-9.

15 Blane $D$. An assessment of the Black report's explanations of health inequalities. Sociology of Health and Illness 1985;7:423-45.

16 Davey Smith G, Shipley M, Rose G. The magnitude and causes of socioeconomic differentials in mortality: further evidence from the Whitehall study. $\mathcal{F}$ Epidemiol Community Health (in press)

17 Office of Population Censuses and Surveys. Mortality statistics: comparison of 8th and 9th revisions of the International Classification of Diseases, 1978 (sample). London: HMSO, 1983. (Series H1 No 10.)

18 Morris J. Four cheers for prevention. Proc R Soc Med 1973;66:225-32.

(Accepted 15 May 1990)

Lesson of the Week

\title{
Concealed haemorrhage in patients nursed on an air fluidised bed
}

\author{
C Clarke, I McConachie, J D Edwards, P Nightingale
}

Fatal occult blood loss may occur when an air fluidised bed is used
Intensive Care Unit, University Hospital of South Manchester, Withington, Manchester M20 8LR

C Clarke, FCANAES, senior registrar in anaesthesia I McConachie, FCANAES, lecturer in anaesthesia J D Edwards, FRCP, consultant physician P Nightingale, FCANAES, consultant in anaesthesia

Correspondence to: Dr Edwards.

BrMed f 1990;301:432
Concealed haemorrhage is a potential cause of inadequate fluid replacement. ${ }^{1}$ We present two cases in which blood drained rapidly into the chamber of an air fluidised (Clinitron) bed. The loss was not obvious despite close clinical supervision and full invasive monitoring in the intensive care unit.

\section{Case reports}

Case 1-A 16 year old boy was admitted after a road traffic accident. He had a degloving injury of his left buttock; fractures of his ankle, pelvis, tibia, and clavicle; a chest injury; and a retroperitoneal haematoma. His injury severity score was 41 . A defunctioning colostomy and skin grafting were performed. During these procedures he required 16 units of blood and coagulation factors but developed a coagulopathy. In the intensive care unit the wounds oozed slowly, necessitating further replacement of blood and blood products and a second operative exploration. After this he was nursed on an air fluidised bed. There was no obvious evidence of external bleeding, but in retrospect the pulmonary artery occlusion pressure and haemoglobin concentration remained low despite further transfusion. For further assessment part of the woven cover sheet of the bed was removed, and the beads were found to be heavily soaked with blood. Further surgery was arranged, but he became acutely hypotensive and had an asystolic cardiac arrest.

Case 2-An 18 year old man who had been trapped in a burning vehicle had $60 \%$ burns to his torso and legs and a smoke inhalation injury. He required transfusion of albumin and blood, and noradrenaline was given to raise the blood pressure. ${ }^{2}{ }^{3} \mathrm{He}$ was transferred to an air fluidised bed for easier nursing care. ${ }^{4} \mathrm{He}$ became suddenly hypotensive. In the absence of visible blood loss this was interpreted as hypovolaemia due to sepsis and was treated as such unsuccessfully. After his death large amounts of blood were found in the bed.

\section{Discussion}

The air fluidised bed is an invaluable aid to managing patients. Its use decreases mortality in certain patients. ${ }^{5}$
Recognised complications of using the bed include excessive drying of wounds, increased evaporative loss of fluid, and confusion due to sensory deprivation. ${ }^{5}$ Occult blood loss into the bed had not been reported before.

The standard woven sheet cover has interstices of around $37 \mu \mathrm{m}$ and is permeable to fluids. Burns units have found it necessary to change the silicon beads frequently. ${ }^{6}$ According to the manufacturers, altered blood is commonly found in the bottom of the beds at servicing. A latex sheet is available, which protects the beads from fluid and silver compounds used in burns care and decreases evaporative loss and drying of wounds. This sheet is recommended as an option by the manufacturers but was not used for these patients.

Both patients had large areas of their body covered with absorbent dressings. As blood leaked into the bed the dressings did not become obviously saturated and no free blood was observed on the bed's surface. Failure to appreciate that haemorrhage was occurring led to inadequate treatment in both cases.

Users of air fluidised beds should be aware that large volumes of blood may be lost into the bed cavity with minimal or no signs of blood accumulating on dressings or on the surface of the bed. Use of a latex sheet should be mandatory for patients at risk. Also, frequent measurements of haemoglobin concentration and packed cell volume are necessary, combined with increased vigilance. This should permit continued safe use of the bed, which has undoubted nursing advantages. ${ }^{4}$

1 Donald I. Practical obstetric problems. 5th ed. London: Lloyd-Luke, 1979: 716-8.

2 Brown C, Edwards JD, Nightingale P, Slater R, Farragher EB. The use of survivors' cardiorespiratory values as therapeutic goals in septic shock. Crit Care Med 1989;17:1098-104.

3 Groenveld ABJ, Nauta JJP, Thijs LG. Peripheral vascular resistance in septic shock: its relation to outcome. Intensive Care Med 1988;14:141-7.

4 Barker SM, Crane R. Nursing burns on special beds. Scand $\mathcal{F}$ Plast Reconstr Surg Hand Surg 1987;21:331-2.

5 Scheulen J, Munster AM. Clinitron air-fluidised support: adjunct to burn care. I Burn Care Rehabil 1983;4:271-5.

6 Normolle E, Storm H. Five years' experience with the air-fluidised bed in the care of burned patients. Scand $\mathcal{F}$ Plast Reconstr Surg Hand Surg 1984;18: $149-51$.

(Accepted 17 April 1990) 